\title{
O trabalho com o texto literário nas aulas de língua espanhola: possíveis contribuições bakhtinianas
}

\author{
The work with the literary text in Spanish language classes: \\ Bakhtinian's possible contributions
}

\author{
Regiane Santos Cabral de Paiva \\ Mestre em Letras e professora de Língua e Literatura Hispanófonas da UERN. \\ Mossoró, RN - Brasil \\ regianeuern@yahoo.com.br
}

\begin{abstract}
Resumo
Este trabalho tratará, sob a ótica bakhtiniana, das contribuições para a compreensão dos conceitos de dialogia, polifonia, heteroglossia, intertextualidade e interdiscursividade, por meio dos quais se podem inferir possíveis aplicações ao ensino, especialmente para o trabalho com o texto literário nas aulas de língua estrangeira, especificamente a espanhola. Para tanto, foi realizado um estudo bibliográfico apoiado em Bakhtin (2000a, 2000b) e em estudiosos de sua teoria: Barros (1999), Bernardi (2001), Bezerra (2008), Brait (2000), Faraco (2009) e Fiorin (2010). A partir dessas observações, este texto ressalta a importância das relações dialógicas para o trabalho com o texto literário, contribuindo, desta maneira, para um estudo mais significativo e competente da leitura, bem como para promover condições essenciais para a leitura responsiva e crítica.
\end{abstract}

Palavras-chave: Dialogismo. Texto literário. Ensino de Língua Estrangeira.

\begin{abstract}
This work concerns, under the Bakhtinian view, contributions for the comprehension of the dialogic concepts, polyphony, heteroglossia, intertextuality, and interdiscursivity, from which it may enable to infer possible applications to teaching, specially for working with the literary text in foreign language classes, specifically in Spanish classes. For that, a bibliographical study was carried out based on Bakhtin's theory and on the works of linguists who study his works such as Barros (1999), Bernardi (2001), Bezerra (2008), Brait (200), Faraco (2009), and Fiorin (2010). From those observations, this work highlights the importance of dialogical relations for working with literary texts, contributing that way, for a more significant and competent study of reading as well as to provide essential conditions for a responsive and critical reading.
\end{abstract}

Key words: Dialogism. Literary text. Foreign language teaching. 


\section{A nascente do rio}

[...] um rio precisa de muito fio de água para refazer o fio antigo que o fez. (João Cabral de Melo Neto, 2003)

O trato com o texto literário (TL) começa a ganhar novas dimensões que vão além do seu papel como recurso para leitura e treino dos aspectos fonéticos e fonológicos da língua. Estudos como os de Pita (1999), Pinheiro (2007) e Fillola (2007) se dedicam a fortalecer o trabalho com o texto literário nas aulas de língua; aprofundando o interesse nessas questões, Paiva e Cabral de Paiva (2010) apresentam o TL para além do recurso didático. Por meio desses estudos, constatamos a possibilidade de se explorar o aspecto cultural; o pragmático que representa o universo literário propriamente dito, no qual o professor pode desenvolver no aprendiz a competência literária explorando o discurso, a forma e o conteúdo; e o campo sociolinguístico que revela aos estudantes diferentes registros de uso da língua, denunciando a região, a classe social, o grupo a que os participantes do texto pertencem.

A partir dessas afirmações, este estudo viu no texto literário um diversificado universo linguístico, cultural, histórico, social e político que possibilita a nós, professores de LE, estreitar a relação com nossos alunos, permitindo-lhes mergulhar num universo íntimo, além de dar-lhes a oportunidade de se revelar como gente, como ser pensante e crítico.

Após constatar os aportes do TL e apreender sua funcionalidade nas aulas de língua, faz-se necessário compreender e perceber todos esses aspectos presentes no texto e olhar para o TL muito além dos seus aspectos funcionais e/ou didáticos. Para tanto, é pertinente observar quais os elementos constitutivos envolvidos na sua construção e elaboração; perceber que ele constitui um rio cuja construção não se dá a partir de uma única nascente d'água, mas de muitos fios de água. Por essa razão, o TL não pode ser trabalhado em sala sem antes conhecermos seu caráter dialógico, polifônico, sem percebermos os aspectos da heteroglossia, da intertextualidade e da interdiscursividade nele presentes.

Dessa maneira, acreditamos que os estudos deixados por Bakhtin são de extrema importância para que, ao tomar em nossas mãos o TL, por exemplo, nós, professores de língua espanhola, nos preparemos melhor para tratá-lo como um lugar de possibilidades para o ensino. Mais que isso, para que o tratemos como rio, não como quebra-mar. 


\section{Dos fios d’água para o rio literário}

Em situação de poço, a água equivale a uma palavra em situação dicionária: isolada, estanque no poço dela mesma, e porque cortou-se a sintaxe desse rio, o fio de água por que ele discorria. (João Cabral de Melo Neto, 2003)

Quando observamos a prática de ensino de LE, após ter lançado um olhar sobre os estudos bakhtinianos, percebemos que o contexto literário (TL) ainda está sendo tratado como um poço, isolado dentro de uma linguagem em que se desconsidera seu momento histórico e as diversas vozes que o constitui. Sendo assim, para que o professor de LE perceba que de dentro dele surgem fios d'água, ele precisa estar atento a determinados aspectos elencados pelo estudioso Mikhail Bakhtin. Ainda mais, durante o trato com o TL ele precisará saber identificálos, relacioná-los a outros fios e explorá-los, de maneira a contribuir para uma compreensão do literário além do campo estético.

Por vezes, temos a boa intenção de levar um texto literário para as nossas aulas de LE a fim de abordar questões de interpretação, trabalhar a leitura ou extrair algum aspecto linguístico relevante para o aprendizado da língua. No entanto, não pensamos que aquele texto é produto de uma interação que se mantém entre o produtor do texto e o contexto. Pior, pensamos que se trata de um texto primeiro, como se as vozes ali presentes pertencessem a um contexto nunca dito antes ou como se os enunciados postos nele fossem inéditos.

É preciso compreender que o texto literário é um objeto que se realiza dentro e a partir de um contexto sócio-histórico em que desaguam várias vozes, obtendo como resultado deste encontro a ligação entre a linguagem e a vida. $\mathrm{O}$ discurso que percorre a sintaxe do "texto rio" é desenvolvido na interação verbal entre enunciador e enunciatário, estabelecendo uma relação de sentido. Daí dizer que Bakhtin concebe o "dialogismo" “[...] como o princípio constitutivo da linguagem e a condição de sentido do discurso [. . . ”" (BARROS, 1999, p. 2).

Qualquer texto é constituído de enunciado, que por sua vez é considerado dialógico, pois todo enunciado se constrói a partir de outro enunciado. Para que se entenda melhor o fluxo do "dialogismo" proposto por Bakhtin, nos apoiamos 
em Fiorin (2008), que apresenta três conceitos-chave a este respeito. O primeiro se relaciona com o modo de funcionamento real da linguagem que compreende o que afirmamos anteriormente: todos os enunciados constituem-se a partir de outros. Logo, quando temos um texto literário, ou não, diante de nós, temos que perceber que dele emerge uma enunciação como resposta a alguma coisa, já que "Não passa de um elo de cadeia dos atos de fala. Toda inscrição prolonga aquelas que a precederam, trava polêmica com ela [.. .]" (BAKHTIN, 2002, p. 98). Assim, a língua, em seu uso real, tem a propriedade de ser dialógica. Fiorin (2008, p. 18-19) esclarece que

Essas relações dialógicas não se circunscrevem ao quadro estreito do diálogo face a face, que é apenas uma forma composicional, em que elas ocorrem. Ao contrário, todos os enunciados no processo de comunicação, independentemente de sua dimensão, são dialógicos. Neles, existe uma dialogização interna da palavra, que é perpassada sempre pela palavra do outro, é sempre e inevitavelmente também a palavra do outro.

Trazendo essa questão para a prática, imaginemos que um professor de língua espanhola decida por trabalhar fragmentos da obra Relato de um náufrago, do escritor Gabriel García Márquez (2003). Primeiramente, ele deve estar atento para o seu discurso, pois nele há muitos enunciados que não pertencem ao autor, mas a outro enunciado trazido pelo verdadeiro protagonista da obra: o sobrevivente do naufrágio que, após ser resgatado, procura um jornalista que publique a sua versão para o desastre com o navio pertencente à marinha colombiana. Após tomar as devidas notas, Gabriel transforma em livro o relato do único sobrevivente desse acidente. Com isso, o professor se certifica de que o texto não trata de um enunciado primeiro, mas de uma extensão da relação dialógica mantida antes da elaboração da obra.

A partir da leitura das obras de Bakhtin, o segundo conceito de dialogismo diz respeito a sua forma composicional: maneiras visíveis de mostrar outras vozes no discurso. Essa inserção dá-se de duas maneiras: como um discurso alheio demarcado (discurso direto, discurso indireto, aspas e negação) e o alheio não demarcado (discurso indireto livre, paródia, pela estilização). No discurso direto, a marcação externa registra nitidamente a voz do personagem e deixa claro que o dito ali não é o ponto de vista do narrador, mas o de quem a proferiu. Além 
disso, nos permite acompanhar o desenrolar dos pensamentos dos personagens. No discurso indireto, os "[...] elementos emocionais e afetivos do discurso não são literalmente transpostos ao discurso indireto, na medida em que não são expressos no conteúdo mas nas formas da enunciação [...]" (BAKHTIN, 2002a, p. 159). Uma peculiaridade dessa construção é que os enunciados interrogativos, exclamativos ou imperativos não se conservam neste tipo de discurso. No caso das aspas, temos a maneira mais nítida de demarcação do discurso do outro, e pela negação, um contraponto de opiniões definido pelo qual o que é dito por um torna-se contrário a partir da negação do outro.

Com a técnica do discurso indireto livre, o narrador mostra o pensamento da personagem, provocando a mistura de duas vozes, pois não há indicadores para demarcar onde começa a fala do narrador e onde termina a da personagem. Para exemplificar melhor, apresento um fragmento da obra, El Señor Presidente, do guatemalteco Manuel Asturias (1970, p. 99): "Un coronel se perdió escalera arriba guardándose el revólver. Otro bajaba por una escalera de caracol guardándose el revólver. No era nada. ¡No era nada! Un capitán pasó por una ventana guardándose el revólver [. . .]". Notemos que, apesar de não haver a identificação clara do início da fala da personagem, percebemos que os enunciados: No era nada. jNo era nada! não são mais pertencentes ao narrador, mas a um coronel que se sente aliviado por não ter que usar sua arma de fogo.

Ainda sobre o discurso não demarcado, é preciso diferenciar a paródia da estilização. No primeiro, trata-se da imitação de um texto com o intuito de desqualificar, ridicularizar ou negar o que está sendo imitado; o segundo também imita, mas sem a intenção de parodiar. Esta imitação compreende um conjunto de particularidades discursivas e/ou textuais. O terceiro conceito de dialogismo, proposto por Fiorin (2008, p. 55), refere-se ao princípio geral bakhitiniano: "[. . . ] o sujeito age em relação aos outros; o indivíduo constitui-se em relação ao outro." Logo, a consciência se constrói na comunicação social, ou seja, na história. O sujeito sempre está em relação ao outro e a percepção do mundo é sempre situada historicamente. E em tal situação o sujeito se constitui discursivamente "[...] apreendendo as vozes sociais que constituem a realidade em que está imerso, e, ao mesmo tempo, suas inter-relações dialógicas [...]" (Ibidem, p. 55). Se a realidade se apresenta de forma heterogênea, o sujeito não absorve apenas uma voz social, mas várias que se relacionam entre si, por isso, afirma-se que o sujeito é constitutivamente dialógico. 
Cada indivíduo tem sua história particular, pois ele é resultante do embate e das inter-relações de vozes de autoridade (aquelas às quais se adere de modo incondicional, que resistem em impregnar-se de outras vozes e a relativizarem-se como a voz da Igreja, do partido etc.) e de persuasão (vozes que se abrem às mudanças). Igualmente, como o sujeito sempre se mantém em relação com o outro, o mundo exterior nunca está acabado ou fechado, "[...] mas em constante vir a ser [...]" (Ibidem, p. 55). Ora, se um professor de LE considera essa visão de sujeito elaborada por meio dos preceitos bakhtinianos, ele jamais pode fechar questões durante uma discussão que parte da leitura de um TL, pois as visões dos estudantes são relativizadas/determinadas pela construção individual que foi elaborada ao longo das suas relações sociais e históricas. O que acontece, na maioria das vezes, é que exigimos do nosso aluno uma leitura específica de um dado TL sem levar em conta a visão de mundo que ele traz consigo e sem antes ter-lhe revelado os elementos necessários que constituíram o texto escolhido.

Outro aspecto inerente aos estudos bakhtinianos que favorece o trabalho com o TL, diz respeito à questão da "polifonia" que, segundo Bakhtin (apud BRAIT, 2000), está presente no gênero romance, por excelência. Este termo foi introduzido pelo pensador soviético para caracterizar o modo novo de narrar de Dostoievski: "[...] a multiplicidade de vozes e consciências independentes e imiscíveis e a autêntica polifonia de vozes plenivalentes constituem, de fato, a peculiaridade fundamental dos romances de Dostoievski [...]" (BAKHTIN, 2002b, p. 4). Para a representação literária, a polifonia representa a supremacia da personagem, pois sua "[. . .] autoconsciência é o traço dominante na construção de sua imagem, e isso pressupõe uma posição radicalmente nova do autor na representação da personagem". (BEZERRA, 2008, p. 193, grifos do autor)

Reconhecer o traço polifônico dentro do romance significa perceber a personagem como ser autônomo, que fala com sua própria voz e que possui sua própria ideologia, mesmo que não coincida com a do autor. No caso do texto ou do romance monofônico, ainda que possuam vários personagens e posições ideológicas diferentes, acabam por expressar a ideologia de um grupo dominante, ou seja, embora nesses romances muitos personagens falem, todos acabam por revelar uma cosmovisão unificada. Nesse sentido, um professor de LE não pode estar alheio a essas questões no momento de trabalhar com algum trecho em prosa de determinado romance, já que reconhecer nele o discurso polifônico 
significa revelar os diferentes cursos ideológicos que se revelam na apresentação dos seus personagens.

Não podemos entender a polifonia como multiplicidade de vozes dentro de um texto ou obra, pois, neste caso, considera-se que há uma "heteroglossia" ou "plurilinguismo". Bakhtin, na verdade, usa este termo para descrever o processo de incorporação de múltiplas vozes quando da enunciação de um texto escrito ou falado. Segundo esse autor, a heteroglossia não importava tanto, mas a dialogização dessas vozes, o encontro sociocultural delas e a dinâmica que aí se estabelece. Também ratifica que o plurilinguismo dialogizado é o verdadeiro ambiente do enunciado, "[...] em que as vozes sociais se entrecruzam continuadamente de maneira multiforme, processo em que se vão também formando novas vozes sociais." (FARACO, 2009, p. 58)

Para maior esclarecimento, Fiorin (2008, p. 82) diferencia essas três denominações:

Dialogismo diz respeito ao modo de funcionamento real da linguagem, que faz um enunciado constituir-se a partir de outro. Heteroglossia e plurivocidade concernem à realidade heterogênea da linguagem e às línguas sociais diversas que circulam numa dada sociedade. A polifonia refere-se à eqüipolência das vozes. A plurivocidade não implica a polifonia, embora a polifonia acarrete necessariamente a plurivocidade.

Tendo em vista essas questões, é preciso considerar que de dentro do TL emergem vozes que foram se constituindo no processo dialógico e que a diversidade de vozes sociais que encontramos nele nos permite entrar em contato com diferentes ideologias, contextos sócio-históricos e aspectos culturais. A polifonia, por sua vez, nos permite reconhecer, dentro dos romances, que os personagens se desprendem dos seus autores, que falam por si mesmos por intermédio de sua autoconsciência e, com isso, os percebemos mais humanos, fazendo com que nos tornemos mais íntimos deles, como se já os conhecêssemos antes mesmo de saber que eles existiam. Tal façanha deve ser revelada pelo professor de LE durante $o$ seu trabalho com o TL em sala, a fim de não deixar seu aluno à margem do rio, mas fazê-lo mergulhar em suas águas e compreender os diferentes cursos por que passou e o fez assim, tão rio, e às vezes tão mar. 
Sobre a constituição deste texto a que chamamos de rio, encontramos dois grandes aspectos que também devem ser levados em consideração no momento da leitura de um texto literário: verificar as questões de "intertextualidade" e de "interdiscursividade". Partindo do que diz Fiorin (2010), esses termos não ocorrem na obra bakhtiniana, e no caso do termo intertextual apareceria uma única vez no conjunto da sua obra. No entanto, graças à tradução da semioticista Júlia Kristeva, o termo intertextualidade ganha prestígio no Ocidente.

Passadas as questões de terminologia, Fiorin utiliza-se de uma reflexão de Santo Agostinho para explicar o problema da intertextualidade e interdiscursividade bakhtiniana: "[...] só se pode falar do que é e não daquilo que não é [...]" (FIORIN, 2010, p.161). Assim, Bakhtin (KRISTEVA apud FIORIN, 2010, p.163) vê "[...] a escritura como leitura do corpus literário anterior e o texto como absorção e réplica a um outro texto [... ]". Dessa maneira, se entroniza a noção de intertextualidade como um constituinte do texto.

É preciso esclarecer, antes, alguns pontos pertinentes ao pensamento do linguista russo: as noções de enunciado, texto e discurso. O primeiro se refere à ordem do sentido e não existe fora das relações dialógicas. O enunciado carrega emoções, juízos de valor, paixões; possui um destinatário e, por isso, permite uma resposta. "O texto é a manifestação do enunciado, é uma realidade imediata, dotada de materialidade, que advém do fato de ser um conjunto de signos [. . .]" (FIORIN, 2008, p. 52). Já o discurso

[...] constitui e é constituído nas práticas discursivas e, por isso mesmo, reflete e refrata o percurso pelo qual o locutor, enquanto sujeito discursivo, situado historicamente e socialmente marcado, é interpelado pela ideologia, que se inscreve nas diversas práticas discursivas. (SOUZA, 2006, p. 3)

A interdiscursividade diz respeito ao diálogo entre discursos ou à forma como determinado tipo discursivo se constitui em relação a outros tipos já conhecidos. Sua dinâmica é sempre interna, implícita, como um discurso que repete temas ou ideias de outro discurso preexistente; trata-se, portanto, do jogo dialógico entre os textos instalados no discurso. Enquanto a "intertextualidade" remete para o processo de construção do sentido por meio, por exemplo, da citação, da alusão 
ou da estilização com intenções parodísticas, a "interdiscursividade" está referida à forma como se constroem os discursos entre si. A intertextualidade pode ser compreendida, então, como o diálogo entre textos, ou seja, a presença de um texto em outro; já a interdiscursividade constitui uma memória discursiva que forma um sentido global para a atividade discursiva. "Por essa razão, a interdiscursividade obriga a um exercício hermenêutico mais complexo do que aquele que se obtém na identificação dos intertextos, mais visíveis e menos sujeitos à soberania do leitor para serem descobertos" (E-DICIONÁRIO DE TERMOS LITERÁRIOS, apud CEIA, 2005).

A interdiscursividade não implica a intertextualidade, mas o contrário é sempre verdadeiro (FIORIN, 2003), porque um texto é sempre um discurso vivo que preexiste a outro texto e que só se torna dinâmico a partir da relação dialógica que se estabelece com outros discursos. Assim, o indivíduo produz textos eminentemente dialógicos e interdiscursivos porque "[. . . todo enunciado possui uma dimensão dupla, pois revela duas posições: a sua e a do outro [...]" (FIORIN, 2010, p. 170). Finalmente, este estudioso ratifica que se chamará qualquer relação dialógica de interdiscursiva, na medida em que se dá uma relação de sentido, ficando reservados à intertextualidade apenas os casos em que a relação discursiva é materializada em textos.

Trazendo para o contexto literário espanhol, encontramos na novela de Cervantes, D. Quixote de la Mancha, uma paródia do estilo literário cultivado na Idade Média, as novelas de cavalaria, e a desmistificação da tradição cavalheiresca e cortês. Neste caso, temos na voz do protagonista um discurso que não pertence à época de sua elaboração (século XVI - Renascimento), mas que predominou do século XIII ao início do XV. Daí o dizer que existe uma materialização linguístico-textual do estilo das novelas de cavalaria com o propósito de satirizá-las. Nesse sentido, temos uma intertextualidade integrada ao texto pelo processo de estilização, na qual, no entanto, não deixa de haver uma interdiscursividade por se tratar de uma relação dialógica entre enunciados. Há de se considerar, principalmente, que se trata de uma obra que traz uma riqueza polifônica com que se expressam seus múltiplos personagens, caracterizados pelo modo de falar e segundo as circunstâncias em que falam. (LÁZARO; TUSÓN, 1988)

Em Bakhtin, ressalta-se que todo discurso dialoga com outro discurso e que toda palavra é cercada de outras palavras. Como exemplo disso, temos a obra de 
Cervantes, a partir da qual outros textos foram se constituindo, como é o caso da novela Quijotita y su prima, do escritor mexicano José Joaquín de Fernandéz Lizardi. Para compreender o porquê de a protagonista ter recebido esse nome, é preciso que se tenha um conhecimento prévio da obra principal para que se abstraia o verdadeiro efeito de sentido.

No poema Un padre nuestro latinoamericano, do escritor uruguaio Mario Benedetti, percebemos que, além da relação intertextual que se estabelece com a oração do Pai Nosso, há um interdiscurso que expressa uma visão que se contrapõe à da oração.

\section{Padre nuestro que estás en los cielos}

con las golondrinas y los misiles

quiero que vuelvas antes de que olvides

cómo se llega al sur de Río Grande

Padre nuestro que estás en el exilio

casi nunca te acuerdas de los míos

de todos modos donde quieras que estés

santificado sea tu nombre

[...]

así en la tierra como en el cielo

siempre

estaré más seguro de la tierra que piso

que del cielo intratable que me ignora.

[...]

no nos dejes caer en la tentación

de olvidar o vender este pasado

o arrendar una sola hectárea de su olvido

abora que es la hora de saber quiénes somos

$y$ han de cruzar el río

el dólar y su amor contrarrembolso

arráncanos del alma el último mendigo

$y$ líbranos de todo mal de conciencia

amén.

(BENEDETTI, 1998, p. 230) 
Pai nosso que estás no céu

Com as andorinhas e os mísseis

Quero que voltes antes que esqueças

Como se chega ao sul do Rio Grande.

Pai nosso que estás no exílio

Quase nunca te lembras dos meus

De todas as formas, onde quer que estejas

santificado seja o teu nome

[...]

Assim na terra como no céu

sempre

estarei mais seguro da terra que piso

que do céu intratável que me ignora.

[...]

Não nos deixes cair na tentação

de esquecer ou vender este passado

ou arrendar uma só hectare do seu esquecimento

agora que é a hora de saber quem somos

e hão de cruzar o rio

o dólar e seu amor reembolsado

arranca-nos da alma o último mendigo

e nos livra de todo mal de consciência

amém.

(Tradução Nossa)

Esse diálogo com a oração do Pai Nosso, a partir da intertextualidade materializada em alguns trechos, tem o intuito de manifestar a indignação do poeta diante das injustiças sociais e políticas vividas na década de 60 do século XX na América Latina. A relação dialógica que se mantém entre o poema e a oração configura o dialogismo que se apresenta entre os dois discursos, em que se percebe claramente a ideologia e o aspecto histórico-social do poema - trata-se de um exemplo claro de interdiscursividade.

Conforme ressalta Kristeva (apud FIORIN, 2008, p. 51), para Bakhtin "[. . . o discurso literário não é um ponto, um sentido fixo, mas um cruzamento de superfícies textuais, um diálogo de várias escrituras, um cruzamento de citações [. . .]". 
Assim, é preciso que o professor de LE esteja atento a essas marcas discursivas para que a apresentação de um texto literário não se perca na superficialidade de estudos linguísticos ou de compreensão leitora que não dirige seu olhar a outras vozes discursivas.

\section{Um curso d'água sem final}

O curso de um rio, seu discurso-rio, chega raramente a se reatar de vez.

(João Cabral de M. Neto, 2003)

Diante das concepções elencadas por Bakhtin e por seus estudiosos, o professor de LE precisa se conscientizar da necessidade de levar em consideração seus princípios ao trabalhar com o TL em sala de aula. Primeiramente, é preciso levar em conta o caráter dialógico do texto, perceber que sua construção é como um rio que se oriunda de muitas nascentes d'água (vozes), e que essas vozes se constroem nas relações dialógicas inseridas em uma situação comunicativa e situadas historicamente. Quando se trata de dialogismo em sua forma composicional, as vozes, em um texto, se apresentam explícita ou implicitamente, por isso, o professor precisa ficar atento ao discurso alheio demarcado e ao alheio não demarcado presentes nos textos literários. Tem-se, então, que um texto sempre dialoga com outro texto, por isso, ele parte sempre do "já dito", o que implica que o professor de língua, ao trabalhar com o TL, deve estar atento às questões de intertextualidade (a relação ocorre entre textos e sua materialidade) e de interdiscursividade (a relação ocorre entre sentidos) que nele se apresentam.

Há de se perceber também que, no TL, pode se manifestar a heteroglossia pelo entrecruzamento das muitas vozes sociais que circulam na sociedade, e que, a partir disso, vão surgindo novas vozes sociais. No entanto, a polifonia se observa quando, num romance, a multiplicidade de vozes e suas consciências independentes não são objeto do discurso do autor, pois se fazem sujeitos do seu próprio discurso.

Tendo em vista essas questões, o professor de língua espanhola precisa trabalhar com o texto literário a partir de uma perspectiva interativa e dialógica, dado que, ao reconhecer os estudos bakhtinianos, a leitura do TL ganhará o caráter responsivo e crítico que merece. Com a compreensão da subjetividade constitutiva 
a partir das relações dialógicas, o profissional também irá promover um ensino de qualidade, na medida em que reconhece seu aluno como um sujeito que está sempre se construindo a partir do outro, e que sua inserção no contexto sóciohistórico irá considerar, diante do texto, que cada um possui um campo visual diferente do outro colega, inclusive do seu próprio. Assim, o professor perceberá que ampliar os vários sentidos do texto é bem mais produtivo do que limitá-lo.

É preciso considerar todas estas questões: dialogismo, heteroglossia, polifonia, intertextualidade e interdiscursividade, por exemplo, para não deixarmos nosso aluno de língua espanhola à margem da compreensão significativa de um TL, mas para que ele possa ter nele um lugar revelador de muitos fios d'água, os quais o levarão a conhecer outras nascentes de rio.

\section{Referências}

ASTURIAS, Miguel Ángel. El senõr presidente. 14. ed. Buenos Aires: Losada, 1970.

BAKHTIN, M. (Volochinov). Marxismo e filosofia da linguagem. 10 ed. São Paulo: Annablume, 2002a.

Problemas da poética de Dostoiévski. 3. ed. Tradução Paulo Bezerra. Rio de Janeiro: Forense Universitária, 2002 b.

BARROS, D. L. P. de. Dialogismo, polifonia e enunciação. In: BARROS, D. L. P, de; FIORIN, J. L. (Org.). Dialogismo, polifonia, intertextualidade: em torno de Bakhtin. São Paulo: EDUSP, 1999.

BENEDETTI, M. Antologia poética. Rio de Janeiro: Record, 1988.

BERNARDI, Rosse-Marye. Uma leitura bakhtiniana de vastas emoções e pensamentos imperfeitos, de Rubens Fonseca. In: FARACO, Carlos Alberto; TEZZA, Cristóvão; CASTRO, Gilberto de. Diálogos com Bakbtin. Curitiba: Ed. da UFPR, 2001.

BEZERRA, P. Polifonia. In: BRAIT, B. (Org.). Bakbtin: conceitos-chave. 4. ed. São Paulo: Contexto, 2008.

BRAIT, B. Anotações em sala de aula. São Paulo: PUC, 2000.

CEIA, Carlos. Interdiscursividade. E-Dicionário de Termos Literários. 2005. Disponível em: http://www.fcsh.unl.pt/invest/edtl/verbetes/I/interdiscursividade.htm. Acesso em: 23 maio 2011.

FARACO, C. A. As ideias linguísticas do círculo de Bakbtin. São Paulo: Parábola Editorial, 2009 . 
FILLOLA, A. M. La utilización de materiales literarios en la enseñanza de lenguas extranjeras. In: GUILLÉN, C. Lenguas para abrir camino. Madrid: Ministerio de Educación, Ciencia Y Deporte. Aulas de verano. Instituto Superior de Formación del Profesorado, 2002, p. 113-166.

. Materiales literarios en el aprendizaje de lengua extranjera. Barcelona: I.C.E. Universitat de Barcelona, 2007.

FIORIN, J. L. de. Introdução ao pensamento de Bakhtin. São Paulo: Ática, 2008.

Intertextualidade e intersdicursividade. In: BRAIT, B. (Org.). BAKHTIN: outros conceitos-chave. São Paulo: Contexto, 2010.

Polifonia textual e discursiva. In: BARROS, Diana L. de Pessoa e FIORIN, J. L. (Org.). Dialogismo, polifonia e intertextualidade. São Paulo: EdUSP, 2003.

KOCH, Igedore G. V. O texto e a construção do sentido. 9. ed. São Paulo: Contexto, 2007.

LÁZARO, F.; TUSÓN, V. Literatura española. Bachillerato 2. Madrid: Anaya, 1988.

MARCUSCHI, L. A. Produção textual, análise de gêneros e compreensão. São Paulo: Parábola Editorial, 2008.

MÁRQUEZ. Gabriel García. Relato de un náufrago. Buenos Aires: Delbolsillo, 2003.

MELO NETO, J. C. Melhores poemas de João Cabral de Melo Neto. Seleção de AntonionCarlos Secchin. 9. ed. São Paulo: Global, 2003.

PAIVA, R. S. C. Texto literário: para além do recurso didático nas aulas de língua. In: COLÓQUIO NACIONAL DE PROFESSORES DE METODOLOGIA DO ENSINO DE LÍNGUA PORTUGUESA E A LITERATURA, 7, 2010, Pau dos Ferros (RN). Anais. . Mossoró: Queima Bucha, 2010, p. 1 a 11.

PINHEIRO, Hélder. A poesia na sala de aula. 3. ed. Campina Grande: Bagagem, 2007. (cap. Sugestões e experiências).

PITA, María Naranjo. La poesía como instrumento didáctico en el aula de español como lengua extranjera. Serie Master E/LE Universidad Complutense. Dirigida por Inmaculada Delgado Cobos.1999.

SOUZA, G. S. de. Algumas reflexões acerca da contribuição de Bakhtin para o sóciointeracionismo da linguagem. In: RODRIGUES, L. de O. et al. SEMANA DE ESTUDO LINGUÍSTICOS E LITERÁRIOS DE PAU DOS FERROS, 5, 2006, Pau dos Ferros (RN). Anais. . Mossoró: Queima Bucha, 2006.

recebido em 9 jun. 2011 / aprovado em 20 jun. 2012

Para referenciar este texto:

PAIVA, R. S. C. O trabalho com o texto literário nas aulas de língua espanhola: possíveis contribuições bakhtinianas. Dialogia, São Paulo, n. 15, p. 107-120, 2012. 